\title{
Postentübasyon sonrası gelişen trakea-özofageal fistül
}

\author{
Tracheoesophageal fistula developing postintubation
}

Erol ÇAKMAK ${ }^{1}$, Hilmi ATASEVEN² ${ }^{2}$ Özlem YÖNEM² ${ }^{2}$, Köksal BILGEN ${ }^{3}$, Hakan GÜZEL ${ }^{4}$

Ordu Üniversitesi Eğitim ve Araștırma Hastanesi ${ }^{1}$ Gastroenteroloji Kliniği, ${ }^{3}$ Genel Cerrahi Klinį̆̆i, Ordu

Cumhuriyet Üniversitesi Tip Fakültesi, ${ }^{2}$ Gastroenteroloji Bilim Dall, Sivas

Dışkapı Yıldırım Beyazıt Eğitim ve Araştırma Hastanesi, ${ }^{4}$ Genel Cerrahi Kliniği, Ankara

Trakea-özofageal fistül, konjenital veya akkiz olan özofagus ve trakea arasında bağlantı olmasıdır. Akkiz trakea-özofageal fistül malign ve nonmalign olmak üzere ikiye ayrllır. Akkiz trakea-özofageal fistül en sık nedeni malignitedir. Non malign trakea-özofageal fistülün en sık nedeni ise uzamış mekanik ventilasyona bağlı endotrakeal kaf ile ilişkili travmadır. Endotrakeal kaf basıncı, ortalama doku kapiller perfüzyon basıncı geçtiğinde lokal trakea mukozasında iskemi ve nekroza neden olur. Hastamı 33 yaşında erkek, organik fosfor zehirlenmesi sonrası uzun süreli endotrakeal entübasyon sonrası gelişen trakea-özofageal fistül idi.

Anahtar kelimeler: Entübasyon sonrası trakea-özofageal fistül, trakea, özofagus

\section{GİRIŞ}

Trakea-özofageal fistül (TÖF), özofagus ve trakea arasında bağlantı olmasıdır. Konjental veya akkiz olarak ikiye ayr1lır. Erişkinlerde çoğunlukla akkiz TÖF görülür. Akkiz TÖF, malign ve nonmalign olmak üzere ikiye ayrılır. Akkiz TÖF sıklıkla maligniteye sekonder oluşur. Non malign TÖF daha az görülür ve en sık nedeni uzamış mekanik ventilasyondur. Uzamış mekanik ventilasyon, endotrakeal kafa bağlı travmalar sonucu oluşur ve non malign trakea-özofageal fistüllerin yaklaşı \% 75 'nin nedenidir $(1,2)$.

\section{OLGU SUNUMU}

33 yaşında erkek hasta intihar amaçlı organafosfor içmesi üzerine acil servisimize başvurdu. Yoğun bakım ünitesinde yatırılan hasta takiplerde solunum yetersizliği gelişmesi üzerine entübe edilerek mekanik ventilasyon desteği uygulandı. Hastaya pralidoksim, atropin ve diğer destekleyici medikal tedavi uygulandı. Hasta 5 hafta sonra mekanik ventilasyondan ayrıldı ve endotrakeal kaf çıkarıldı. Hastada sıvı alımı sonrası öksürük, disfaji, odinofaji, nefes darlığı ve pürülan balgam görüldü. Hastanın fizik muayenesinde; taşikardi, takipte, ateş $\left(39^{\circ} \mathrm{C}\right)$ ve bilateral diffüz ronkus saptandı. Yapılan tetiklerde kanda, hemoglobin: $15.3 \mathrm{gr} / \mathrm{dl}$, lökosit: 24.710/ mm3 (\%90 parçalı) olarak saptandı. Hastanın balgam kültüründe Pseudomonas auregenosa üredi ve pnömoni teşhisi konuldu ve antibiyotik tedavisi başlandı. Hastaya yapılan özo-
Tracheoesophageal fistula, congenital or acquired, is a connection between the esophagus and trachea. Acquired tracheoesophageal fistula is divided as malignant and nonmalignant. The most common cause of acquired tracheoesophageal fistula is malignancy, while the most common cause of nonmalignant tracheoesophageal fistula is trauma associated with endotracheal cuff during prolonged mechanic ventilation. When the pressure in an endotracheal cuff balloon exceeds the capillary perfusion pressure, it causes ischemia and necrosis in the local tracheal mucosa. Our patient was a 33-year-old male with tracheoesophageal fistula developing after long-term endotracheal intubation for organic phosphorus poisoning.

Key words: Postintubation tracheoesophageal fistula, trachea, esophagus

fagografide oral kontrast maddenin trakeaya geçtiği görüldü. Hastaya Olympus GIF -Q160 cihazı ile yapılan endoskopide; vokal kordlar görüldü, piriform fossanın altından geçildiğinde normalde özofagus mukozası görülmesi gerekirken birbirine paralel şekilde seyreden hem trakea boşluğu hemde daralmış özofagus lümeni görüldü (Resim 1). Hastada uzun süreli entübasyona bağll trakea-özefageal fistül geliştiği düşünüldü. Hastaya trakea rezeksiyonu-rekonstrüksiyonu ve özofagus tamiri yapıldı. Hastanın postop takiplerinde anastomoz hattinda yırtık saptandı ve metalik stent takıldı. Hasta 10 gün sonrasında aynı şikayetlerle gelmesi üzerine total özofajektomi ve dil köküne hazırlanmış mide anastamozu yapıldı. Hasta operasyon sonrası takiplerinde sol akciğerde plevral sıvı saptandı ve tüp torakostomi ile serohemorajik mayi boşaltıldı. Hasta tekrar operasyona alındığında midenin nekroze olduğu görüldü ve sepsis nedeniyle kaybedildi.

\section{TARTIŞMA}

Trakea-özofageal fistül, özofagus ve trake arasında bağlantı olmasıdır. Nonmalign TÖF'ün en sık nedeni ise uzamış mekanik ventilasyondur $(1,2)$. Endotrakeal entübasyonun sekonder major trakeal komplikasyonu \%0,3-19 oranındadır. Bu major komplikasyonlar; trakea-özofageal fistül, trakeal stenoz, trakea innominate arter fistülü ve cuff trakea ektazisidir. TÖF gelişmesi entübasyon sonrası 12-200 günler arasın- 


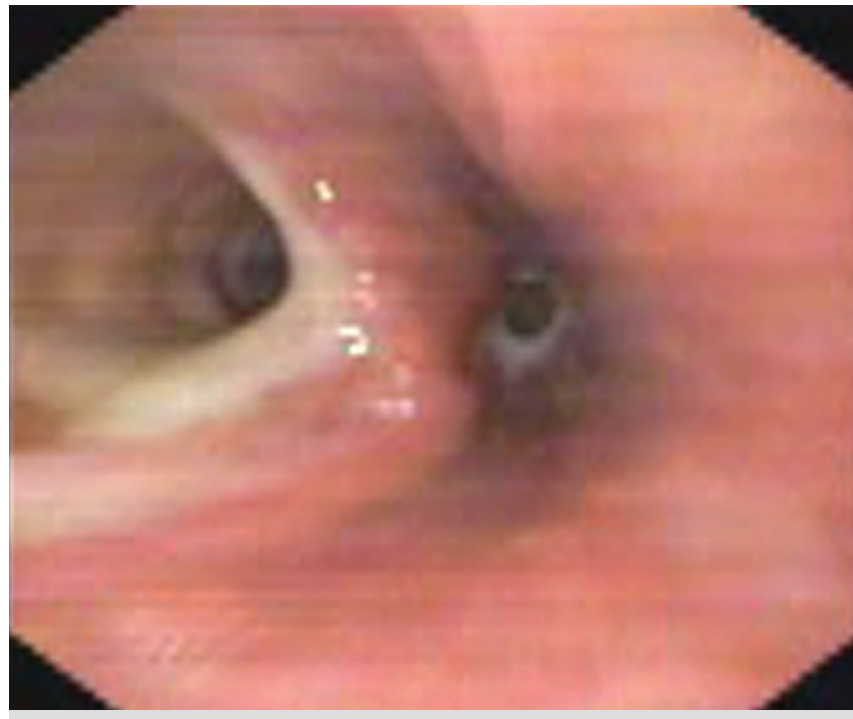

Resim 1. Endoskopik trakea-özofageal fistül görünümü

da ve ortalama 40 günde gelişir. Bizim hastamızda entübasyon sonrası TÖF 35 . günde tesbit edildi $(3,4)$.

Endotrakeal tüp kafı 2-12 mmHg volumle şişirilir ve 20 mmHg geçmeyecek şekilde basınç uygulanır. Endotrakeal kaf basincı, ortalama doku kapiller perfüzyon basincı olan 20 mmHg geçtiğinde lokal trakea mukozasında irritasyona neden olur. Bu irritasyon sonucu iskemi, nekroz ve sonrasında TÖF meydana gelir. Ayrıca nadiren trakea-özofageal mesafede abse oluşumu sonrası masif trakeal nekroz ve dev fistüle neden olabilir $(1,4,5)$.

Nonmalign TÖF'ün oluşumunda primer olarak granülomatöz enfeksiyonlar, insan bağışıklık yetmezlik virüsü enfeksiyonu, travma, önceki cerrahi ve endoskopik girişimler neden olabilir. Ayrıca akkiz TÖF gelişimine eşlik eden birçok predispozan faktörler mevcutdur. Bunlar arasında; sistemik ve respiratuvar infeksiyonlar, hastanın kötü genel durum ve beslenme yetersizliği, koroziv madde içilmesi, nazogastrik tüp, diabetes mellitus ve streoid tedavisidir. Enfeksiyonlar TÖF gelişiminde primer ve sekonder nedenler olarak rol oynar (4-6).
TÖF oluşumuna neden olan diğer predispozan faktörler; endotrakeal hastalarda TÖF'ün ilk belirtisi sıklıkla beslenme veya mide içeriğinin aspirasyonu sonucu aniden trakeal sekresyonda artışıdır. Semptomlar ve belirtiler sıvı alımı ve yemek yeme sırasında öksürük, yutma güçlüğü, ateş, pnömoni, hemoptizi ve göğüs ağrısıdır. Bizim olgumuzda ilk belirti sıvı alımı sonrası öksürük ve yutma güçlüğü idi. TÖF düşünülen hastalarda teşhis amaçlı en sık kontrastlı tetikler uygulanır. Ancak endoskopi uyutulmayan hastalarda en iyi tetkik yöntemidir. Kontrast madde defektleri \%70 oranında göstermektedir. Bu tetkikler ile TÖF'ün yeri, boyutu ve yönü saptanır. Ancak küçük boyutlu TÖF'lü olgular endoskopi ve kontrastlı tetikler ile fark edilmeyebilir. Bu hastalarda bronkoskopi faydalı olabilir $(2,7)$.

TÖF'lü hastalar malign olmamasına rağmen ölümcül komplikasyonlara neden olabilir. Bu nedenle başarılı müdahale ve mortalite açısından erken tanı ve erken cerrahi çok önemlidir. En sık görülen komplikasyonlar aspirasyon pnömonisi ve akciğer absesidir. Bu komplikasyonlar sonucunda sepsis ve hemoraji gibi ölümcül komplikasyonlara neden olabilir (2, $5,6)$

TÖF'lerin spontan olarak kapanmaları nadirdir ve genelde cerrahi olarak kapatılmaları gerekir. TÖF küçük ise primer tamir edilir ve kas flebi kullanılarak yapılır ise tedavi şansını artırır. Ancak geniş TÖF'de ise trakeal rezeksiyon gerekir. Ancak opere edilemeyen malign hastalarda endoskopik olarak takılabilen plastik veya kendiliğinden genişleyebilen metalik stent tercih edilebilir. Bu sayede pulmoner aspirasyonun önüne geçilebilir. Ayrıca uygun benign özofagorespiratuvar fistüllerde de özofagusa stent uygulaması yapılabilir $(2,7,8)$.

Sonuç olarak uzun süreli endotrakeal entübeli hastalarda, entübasyon sırasında ve sonrasında sıvı alımı sonrası öksürük ve yutma güçlüğü görülen hastalarda TÖF olabileceği düşünülmelidir. Ayrıca endotrakeal entübeli hastalarda, endotrakeal kaf basıncı sık sık kontrol edilerek 20 mmHg altında olmasina dikkat edilmelidir.

\section{KAYNAKLAR}

1- Diddee R, Shaw IH. Acquired tracheo-oesophageal fistula in adults. Contin Educ Anaesth Crit Care Pain 2006; 6: 105-8.

2- Chauhan SS, Long JD. Management of tracheoesophageal fistulas in adults. Curr Treat Options Gastroenterol. 2004; 7: 31-40.

3- Marzelle J, Dartevelle P, Khalife J, et al. Surgical management of acquired post-intubation tracheo-oesophageal fistulas: 27 patients. Eur J Cardiothoracic Surg 1989; 3: 499-502.

4- Abbey NC, Green DE, Cicale MJ. Massive tracheal necrosis complicating endotracheal intubation. Chest 1989; 95: 459-60

5- Collier KP, Zubarik RS, Lewis JH. Tracheoesophageal fistula from an indwelling endotracheal tube balloon: a report of two cases and review. Gastrointest Endosc 2000; 51: 231-4.

6- Payne DK, Anderson WM, Romero MD, et al. Tracheoesophageal fistula formation in intubated patients. Risk factors and treatment with highfrequency jet ventilation. Chest 1990; 98: 161-4.

7- Couraud L, Ballester ML, Delaisement C. Acquired tracheoesophageal fistula and its management. Semin Thorac Cardiovasc Surg 1996; 8: 392-9

8- Yakut M, Çınar K, Idilman R. Malign özofagus darlığı olgusunda multipl stent uygulaması. Endoskopi dergisi 2011; 19: 18-9. 